\title{
In-process force monitoring for precision grinding semiconductor silicon wafers
}

\section{Jeremiah A. Couey and Eric R. Marsh*}

Machine Dynamics Research Laboratory,

The Pennsylvania State University,

21 Reber Building, University Park, 16802 PA, USA

E-mail: jeremiahcouey@yahoo.com

E-mail: emarsh@psu.edu

${ }^{*}$ Corresponding author

\section{Byron R. Knapp}

Olympic Laser, Inc., 410 Ida Street West,

Bremerton, WA 98312, USA

E-mail: byron.knapp@extrudehone.com

\section{R. Ryan Vallance}

Precision Systems Laboratory, The George Washington University, 738 Phillips Hall, 801 22nd St. NW, Washington DC, 20052, USA

E-mail: vallance@gwu.edu

\begin{abstract}
Forces generated during precision wafer grinding are small and present challenges for accurate and reliable process monitoring. In this work, these challenges are met by incorporating noncontact displacement sensors into an aerostatic spindle that is calibrated to measure grinding forces from the relative motion between the spindle rotor and stator. This arrangement allows the calculation of grinding forces without introducing compliance into the structural loop of the grinding machine. Aerostatic spindles are used in precision wafer grinding requiring high stiffness and very low error motions $(5-25 \mathrm{~nm})$. Several experiments evaluate this force sensing approach in detecting workpiece contact, process monitoring with small depths of cut, and detecting workpiece defects. The results indicate that force measurements offer good performance for monitoring precision wafer grinding since this approach provides excellent contact sensitivity, high signal resolution, and has sufficient bandwidth to detect events occurring within a single revolution of the grinding wheel.
\end{abstract}

Keywords: silicon wafer grinding; grinding process monitoring; grinding sensors.

Reference to this paper should be made as follows: Couey, J.A., Marsh, E.R., Knapp, B.R. and Vallance, R.R. (2005) 'In-process force monitoring for precision grinding semiconductor silicon wafers', Int. J. Manufacturing Technology and Management, Vol. 7, Nos. 5/6, pp.430-440. 
Biographical notes: After serving at a Graduate Research Assistant in Penn State's Machine Dynamics Research Lab, Jeremiah Couey (MSME, Penn State 2003) accepted a position as a Staff Scientist at Dalhousie University in Halifax, Nova Scotia.

Eric Marsh (PhD, MIT 1994) is the Director of the Machine Dynamics Research Lab at Penn State. His research focuses on grinding process instrumentation for precision applications.

Byron Knapp (PhD, Penn State 2002) served as a Graduate Research Assistant in the MDRL and is now a Senior Mechanical Engineer at Olympic Precision in Bremerton, WA.

R. Ryan Vallance (PhD, MIT 1998) is the Director of the Precision Systems $\mathrm{Lab}$ at The George Washington University. His research focuses on precision engineering and metrology, especially for micro and nano technology.

\section{Introduction}

Ultra precision machining is defined by processes providing the highest possible dimensional accuracy at a given point in time. For example, manufacturers of photolithography lens assemblies require optical components with nanometre form error and Angstrom surface finish. To achieve those tolerances, manufactures typically use lapping, polishing, grinding, single point diamond turning, or honing operations. Monitoring each of these processes is complex, due to the low material removal rates and complex workpiece-tool interaction. This paper describes work which is focused on monitoring ultra precision rotary grinding of silicon wafers, where sub micrometer geometric form errors and nanometre level surface finishes are obtained using fixed abrasives and machines with high static and dynamic stiffness, high resolution controls, and environmental isolation systems.

Monitoring wafer grinding provides a better understanding of the complex brittle material removal process. Additionally, process monitoring enables throughput optimisation, inline quality analysis and decreased manufacturing costs. In recent research, Oliveira and Valente found that there still remains a need for a grinding control parameter that quickly detects short process variations and reliably represents the grinding energy (Oliveira and Valente, 2004; Dornfeld et al., 2003). However, monitoring of precision wafer grinding with its very low forces and material removal rates is complicated by the resolution limits of commercially available sensors. Furthermore, the rotation of both the workpiece and abrasive wheel in face grinding present challenges in the proper instrumentation of the process. This paper illustrates that grinding forces may be conveniently measured with force sensing air bearing spindles that enable nanometre level contact detection and direct correlation to the grinding process. Experiments demonstrate the performance of this monitoring approach for workpiece contact detection, ultra fine grinding and defect detection. 


\section{Background}

The forces generated in grinding are directly proportional to the grinding energy, which Malkin found to depend on three processes: chip formation, plowing, and sliding (Malkin, 1989). However, wheel loading and grit wear increase over time, which changes the relative proportion of the three energy components. Furthermore, properties of brittle materials can complicate the grinding process. For example, silicon is an anisotropic crystal whose material properties vary as a function of crystallographic orientation, which causes machining properties like the critical chip thickness or the ductile to brittle cutting transition depth, to vary with the crystal orientation. In previous research, the critical chip thicknesses of monocrystalline electronic grade silicon were experimentally measured and found to vary from $40 \mathrm{~nm}$ to $120 \mathrm{~nm}$ on the (001) cubic face in a single point diamond flycutting experiment (O'Connor et al., 2005). In brittle material grinding, this ductile and nonductile cutting process, complicated by the complex chip formation, is responsible for the wafer subsurface damage that plagues the industry. Furthermore, the geometry and cutting dynamics of the wafer grinding process, seen in Figure 1, plays a very significant role in the wafer form and surface quality. Recent wafer processing research has focused on the roles of each of these components in analytically predicting wafer shape and quality. For example, Pei et al. has done significant research in understanding the geometrical parameters of the workpiece chuck shape, the wafer shape and the process parameters (work speed, wheel speed, feed rate, abrasive grit size, coolant geometry) for fine grinding (Pei and Strasbaugh, 2001, 2002; Chidambaram et al., 2003a, 2003b; Sun et al., 2004). In addition, Lin et al. (2003) simulated the molecular dynamics of nanometre scale grinding of brittle materials.

Figure 1 The geometry and cutting dynamics of rotational grinding

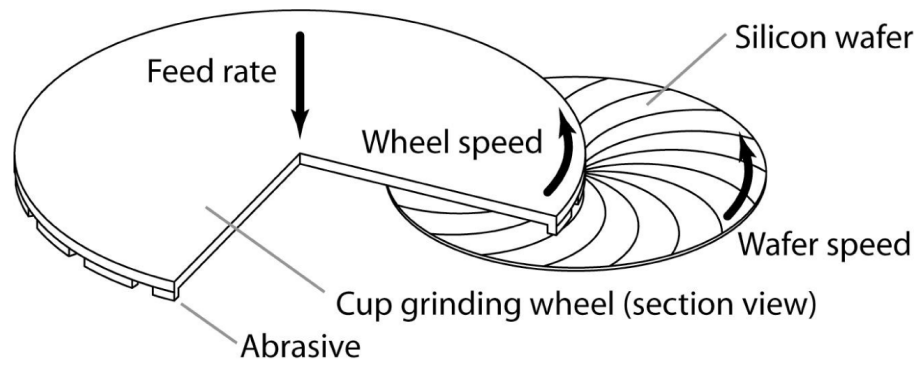

Given the complex material removal processes and the rotational geometry in wafer grinding, monitoring is necessary to automate and optimise the process because of demands for increase in productivity and quality. Tonshoff et al. (2002) concluded that industrial grinding monitoring is necessary due to the difficulties of predicting workpiece quality because modelling the large number of cutting edges undergoing nonuniform wear in a transient manner is extremely difficult.

The 2002 review of grinding monitoring by Tonshoff et al. (2002). Tonshoff et al. (2002) found that there are a multitude of measurement systems used to measure grinding processes such as acceleration, acoustic emission, temperature, force, power, workpiece form and surface integrity, and the macro and micro topography of the active abrasive layers of the grinding wheel. Among all of the possible sensors, acoustic emission (AE) measurement has been the most popular approach used to monitor 
grinding processes for the last two decades. AE sensors offer advantages such as low cost and easy installation, with no reduction in machine tool stiffness.

Monitoring grinding processes with force measuring instrumentation is generally more expensive than acoustic emission systems, so it is most often used in process development and research applications. For example, three component force measurement is a popular technique for validating models of surface grinding, since the setup is simple and high quality dynamometers are commercially available. For cylindrical and axial plunge grinding operations, researchers historically built custom force measurement systems, although commercial rotating dynamometers are now available Kistler Instrument Company. ${ }^{1}$ In the past, grinding force measurement systems were built using the calibrated output of strain gages (Chen et al., 1984; Li et al., 2002), piezoelectric crystals (Bell et al., 1984; Drew et al., 2002), pressure sensors (Lezanski et al., 1993; He, 1985), and displacement sensors such as LVDTs and capacitance probes (Marsh et al., 1998, 2000; Knapp, 2002; Couey et al., 2005; Ramos et al., 2001). Force measurements rely on a compliant component in the structural loop. Some of these force sensors introduce additional structural compliance to obtain high sensitivity that may cause unwanted effects on the process.

It is beneficial to have real time grinding force feedback available in precision grinding applications because of the direct correlation to the grinding energy. For example, many axial plunge grinding operations are difficult to optimise because the operator receives almost no detectable feedback from inspection of the process. Visual and audible feedback can be overwhelmed by machine noise and coolant spray because of the high spindle speeds and small depths of cut. For precision wafer grinding, a suitable real time grinding sensor system must have sufficient resolution to detect changes in the grinding force at the subNewton level and must have sufficient bandwidth to properly characterise various grinding events including touchoff, workpiece cleanup, and vibration. Furthermore, it is desirable that the grinding sensor system be sensitive to even static and quasistatic changes so that very slowly changing parameters, such as wheel wear and thermal growth, can be properly monitored.

In this work, we use noncontact, high sensitivity capacitive displacement sensors to measure relative displacements between the rotor and stator of the workpiece spindle. This approach is stable, robust, accurate, and offers excellent resolution for the low cutting forces encountered in precision grinding. The instrumented spindle built for this work provides real time force measurement with $200-\mathrm{mN}$ resolution and DC to $300 \mathrm{~Hz}$ bandwidth. Furthermore, this approach of force measurement does not reduce the structural loop stiffness of the grinding machine, is not intrusive to the grinding process, and allows measurement of static and quasistatic grinding forces that are difficult to determine using piezoelectric ceramic force transducers.

The following sections describe the details of the experimental setup and present results from three experiments that evaluate the viability of the force based measurements. These results illustrate the utility of a force sensing spindle in monitoring precision wafer grinding.

\section{Experimental setup}

The instrumented air bearing spindle used in these experiments measures axial and tilt forces, but is similar to previous instrumented spindles that sense radial forces in 
precision grinding (Marsh et al., 1998, 2000; Knapp, 2002). Figure 2 shows the instrumented spindle designed specifically for measuring wafer grinding forces during precision plunge grinding. The design features an aerostatic spindle (Professional Instruments 4R) with a frameless, brushless, DC motor and a 6 mrad resolution resolver for synchronised data acquisition. Figure 2 also displays the four stator-embedded, high-resolution capacitive displacement sensors $(1 \mathrm{mV} / \mathrm{nm}$ Lion Precision C1-C) that target the rotor. This arrangement allows direct rotor to stator axial and tilt displacement measurement without compromising the structural loop stiffness. The design has four capacitance probes, but only two probes located $90^{\circ}$ apart were used for these experiments.

Figure 2 The instrumented air bearing work spindle. The section view displays the spindle stator with four axial embedded capacitance probes for sensing grinding force induced changes in the rotor stator gap distance. The capacitance probes target against the trust plate of the rotor

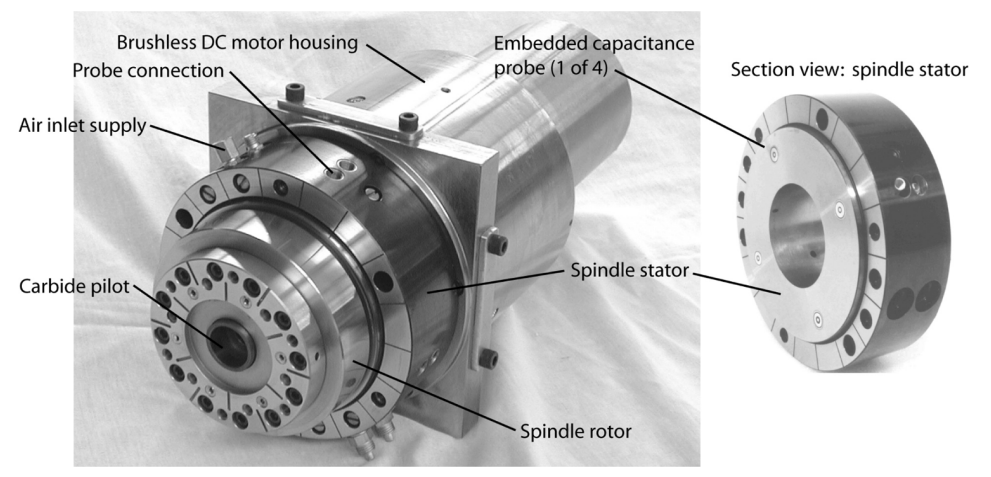

All experiments were carried out on a two axis grinding machine (Moore 450 CNC) with a programmable resolution of $0.1 \mu \mathrm{m}$. Figure 3 shows the machine with the work and grinding spindles. During experiments, the grinding area is generously flooded with an emulsion coolant.

Figure $3 \mathrm{CNC}$ face grinding machine with wheel and work aerostatic spindles

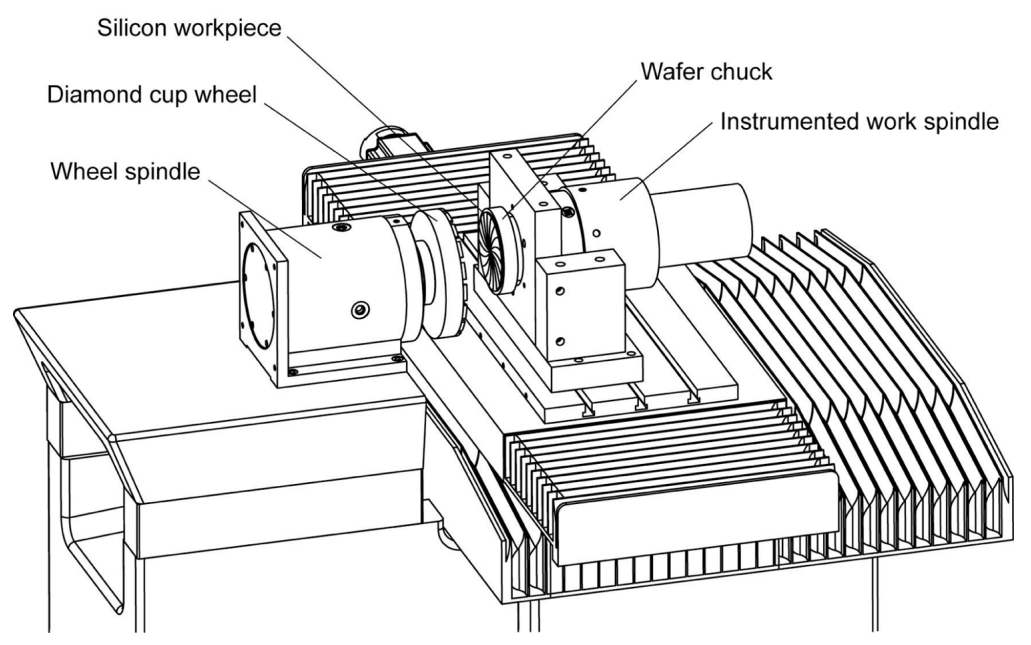


The instrumented spindle measures the relative motion between the work spindle stator and rotor. The spindle axial and tilt stiffness are predetermined, so the force values are computed directly by real time analysis software. An additional consideration is that the capacitance sensors target the rotating spindle rotor that has $300 \mathrm{~nm}$ form error. The software removes this form error automatically using the rotary resolver for synchronisation. Data acquisition and analysis is carried out by custom LabWindows/CVI software with true real time force feedback. The user interface, which provides complete control of the instrument and data analysis on a single screen, is shown in Figure 4.

Figure 4 Custom designed software for real time grinding force feedback adaptable to wafer grinding

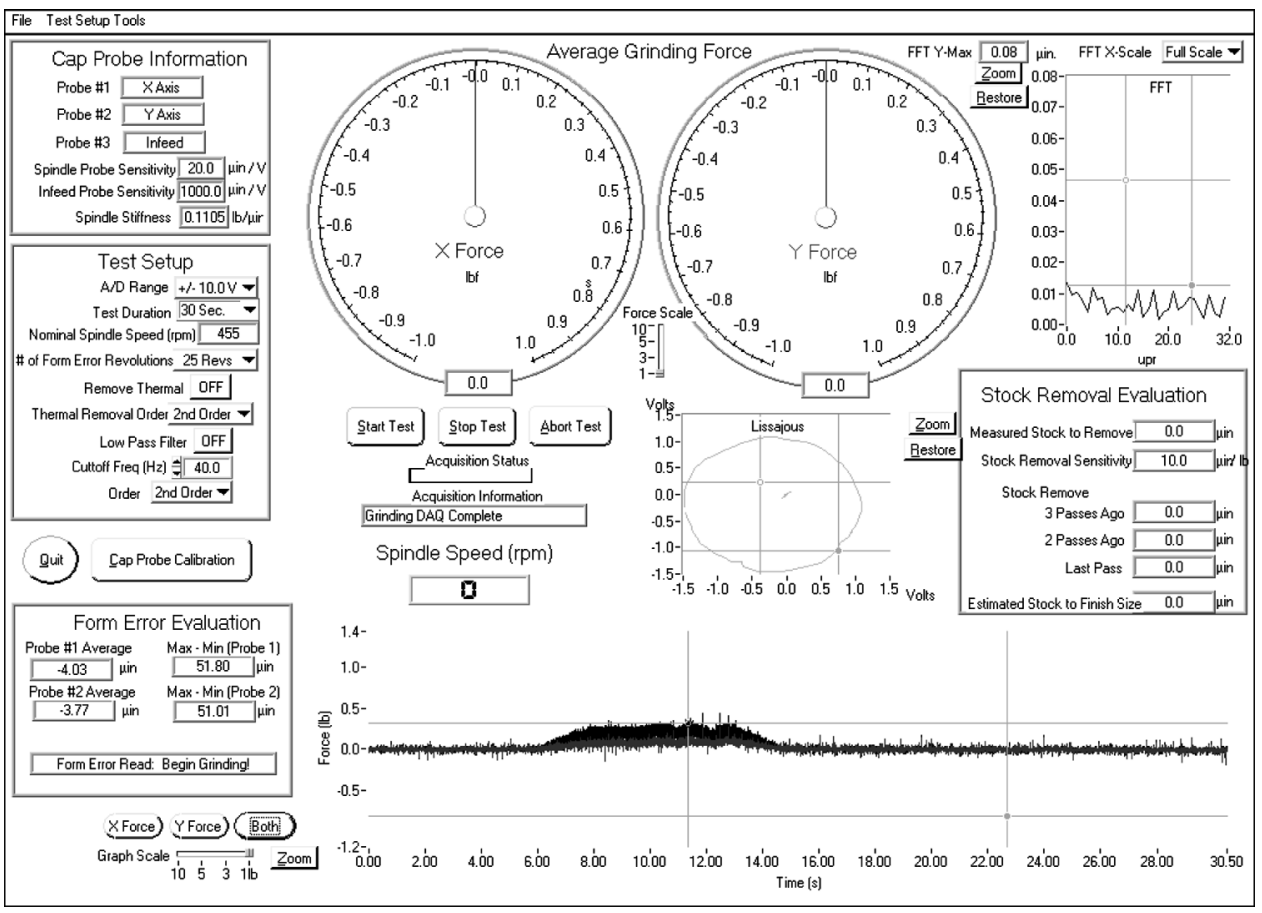

Plunge grinding experiments were conducted for this research on $\varnothing 50 \mathrm{~mm}$ (100) silicon wafers. The work spindle rotates at 500 RPM and the abrasive wheel operates at 3450 RPM. Two types of resin bond super abrasive wheels are used for the experiments. One wheel is a $\varnothing 140 \mathrm{~mm}, 2000$ grit segmented synthetic diamond wheel (Noritake SD $2000 \mathrm{~V} 35$ BW6 5.0), and the other is a $\varnothing 100 \mathrm{~mm}, 400$ grit synthetic diamond wheel (Noritake SDC 400 P 100 BW4 15.0). The abrasive wheels are dressed with an aluminium oxide dressing pad before each experiment. The feed rates and plunge depths vary and are reported individually for each experiment. 


\section{Experimental results}

The first experiment explores the resolution and sensitivity of the instrumented spindle. A light load is applied by a cotton swab to the spinning wafer, with intermittent contact. Force data from one capacitance probe is shown in Figure 5. The light contact is typical of the forces seen in initial workpiece contact and sparkout in precision grinding in previous experiments. The plot indicates that the calculated force readily detects workpiece contact. Furthermore, this test demonstrates the milliNewton force resolution of the instrumented spindle. A $400 \mathrm{mN}$ force, corresponding to a relative displacement of two nanometres between the spindle rotor and stator, is readily detected.

Figure 5 Sensor output under a very light interrupted axial load showing the force measurement resolution

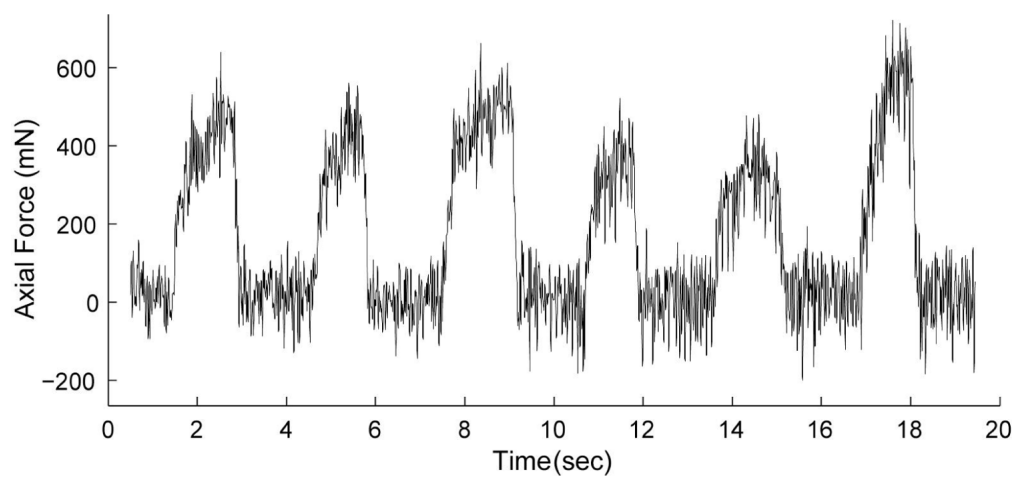

Results from a second experiment, shown in Figure 6, further demonstrate the resolution and range of the force sensor in detecting contact between the grinding wheel and workpiece. In this experiment, successive low force plunge grinds were made with the 400 grit diamond wheel. The axial feed rate doubles between plunges and the feed rates vary from 0 to $0.64 \mathrm{~mm} / \mathrm{min}$. The depth of cut was increased to allow equal cutting durations for each plunge. In the first plunge, the grinding wheel is not fed into the wafer, in order to show nongrinding conditions where coolant interaction and machine electrical noise dominate the signal. In addition, the section view of the $0.32 \mathrm{~mm} / \mathrm{min}$ plunge grind displays the intrarevolution characteristics of the force signal for three workpiece revolutions. The force signal clearly shows a repeatable, cyclical wheel-workpiece interaction synchronous with the rotation of the grinding wheel. This same wheel-synchronous fluctuation is commonly seen in surface grinding force measurements taken with three-component dynamometers. Also seen in the figure, accurate contact detection is achieved for the $0.04 \mathrm{~mm} / \mathrm{min}$ plunge grind and the mean grinding force scales linearly with the axial feed rate.

Figure 7 presents the same data in the frequency domain to examine the change in force spectra. The wheel speed $(58.5 \mathrm{~Hz})$ and its harmonics dominates the force spectra and increases in magnitude with increased feedrate. Additionally, the work speed $(8.3 \mathrm{~Hz})$ and its harmonics do not contribute significantly to the force spectra below the $0.32 \mathrm{~mm} / \mathrm{min}$ feedrate. Furthermore, the low frequency force spectra, seen at the start and finish of each plunge (seen easily in the $0.64 \mathrm{~mm} / \mathrm{min}$ data), corresponds to plowing/rubbing grinding energy as the wheel engages/disengages with the workpiece 
due to the inherent machine and workpiece material compliance. Note that the dominant first two frequency bins (static and quasi-static force components) are not shown and the plot has been rescaled to ease examination of the higher frequency characteristics.

Figure 6 Axial grinding force obtained with a 400 grit $(30 \mu \mathrm{m})$ diamond wheel on a $\varnothing 50 \mathrm{~mm}$ silicon workpiece. The mean grinding force scales linearly with the axial feedrate

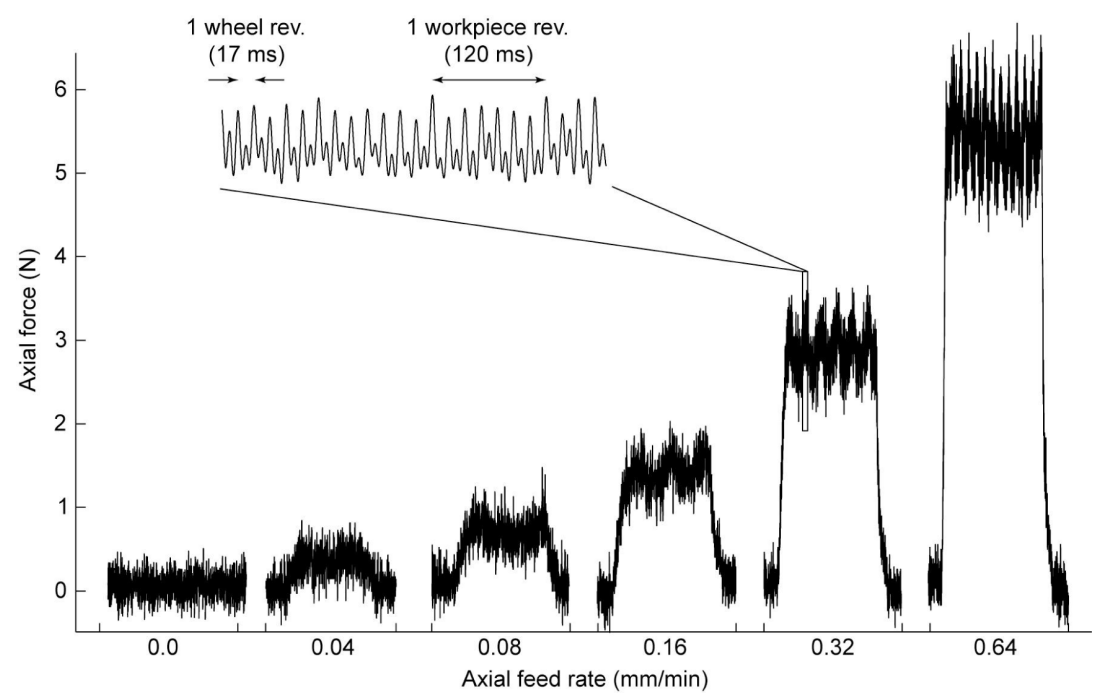

Figure 7 Waterfall plots showing changes in grinding force spectra as the feedrate is doubled
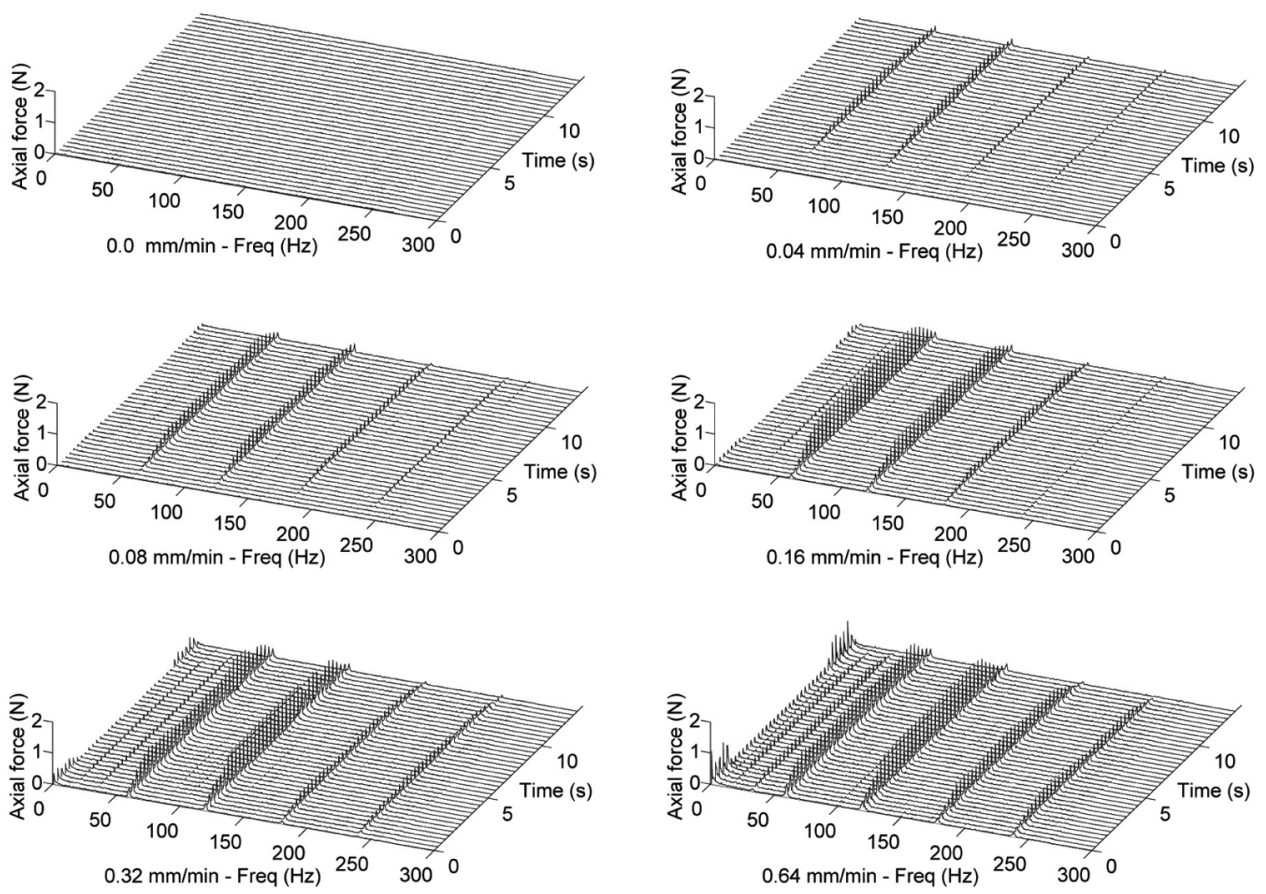
The third experiment examines the ability of the instrumented spindle to detect workpiece defects. A nonflat silicon wafer is ground until the defect is sufficiently removed. The initial workpiece nonflatness was $50 \mu \mathrm{m}$ and the plunge rate was $0.64 \mathrm{~mm} / \mathrm{min}$ with the 400 grit segmented abrasive wheel. The force data is presented in Figure 8. The first 4.5 seconds of the grind is required to remove the defect, and then workpiece sparkout is initiated. The workpiece defect is clearly detectable, since the cutting force drops to zero, as the wheel rotates over the defect. As can be seen in the figure, grinding cycles can be optimised to remove the minimum amount of material by monitoring intrarevolution fluctuations in grinding force with the instrumented spindle.

Figure 8 Axial grinding force while face grinding a silicon wafer with some initial nonflatness. At 4.5 seconds sufficient material has been removed to eliminate the defect

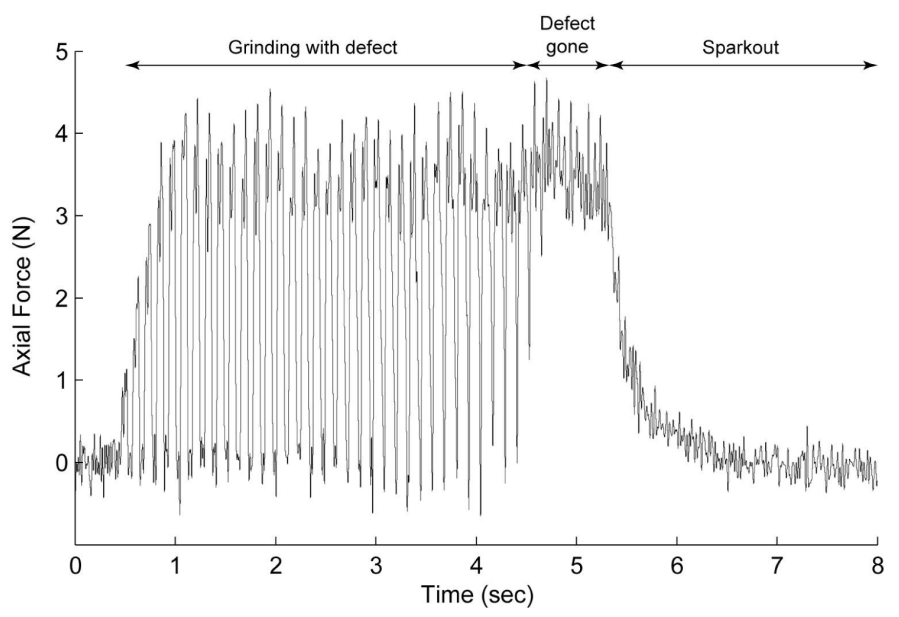

Figure 9 shows the same data plotted in the frequency domain as a waterfall plot. The figure shows the $8.3 \mathrm{~Hz}$ frequency component and its harmonics, indicating the presence and eventual removal of the workpiece low spot in the normal force data. The spectral content, at 5 seconds, changes to show complete defect removal. Upon removal of the low spot, the surface roughness for this workpiece $R_{a}=18 \mathrm{~nm}$ with a 400 grit wheel.

Figure 9 Waterfall plot showing changes in grinding force spectra as a workpiece defect is eliminated through material removal

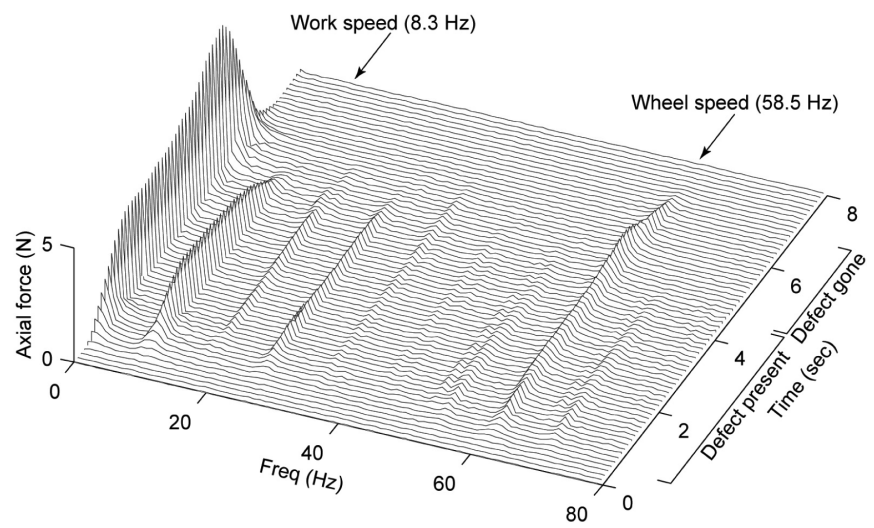




\section{Conclusion}

Monitoring wafer grinding is advantageous in optimising process conditions, improving process control, and producing high quality parts. This is challenging in precision applications where aerostatic spindles and small depths of cut are common. Detecting small forces with a conventional force sensor requires a compliant element in the machine's force loop, which reduces machine stiffness and degrades precision. Commercial AE sensors, which do not degrade machine stiffness are more common in industry monitoring systems, but they are less sensitive when grinding with aerostatic spindles, where rotor vibrations are not transferred to the spindle housing via mechanical contact.

This paper demonstrates that a force based solution that does not degrade machine stiffness is achievable by instrumenting an aerostatic spindle with noncontact capacitive displacement sensors that measure rotor motion caused by axial grinding forces. The force resolution of the instrumented spindle was experimentally determined to be $200 \mathrm{mN}$, which corresponds to detecting a one nanometre spindle rotor deflection.

Several experiments demonstrate the advantages of the force sensing spindle for process monitoring. The measurement system was evaluated for workpiece contact detection, sensor range characteristics, and sensitivity in detecting unground low spots on the workpiece. Based on the results, the force feedback system displays excellent monitoring characteristics in all of the experiments. The force sensing spindle accurately detected workpiece contact at a nanometer resolution, and the measured forces correlated well with axial feed rates from $40 \mu \mathrm{m} / \mathrm{min}$ to $640 \mu \mathrm{m} / \mathrm{min}$. Experiments also demonstrated that the force sensing approach can provide real time feedback sufficient to observe unground low spots on the wafer for process optimisation. Therefore, for precision wafer grinding, feedback from a force sensing spindle provides quick, robust, and reliable process monitoring capabilities that have direct correlation to the material removal mechanisms and the grinding energy.

\section{References}

Bell, W.F., Lambert, E.L., Matson, C.B. and Vaillette, B. (1989) 'High rate internal grinding machine instrumentation and data acquisition', Carbide and Tool Journal, Vol. 21, No. 2, pp.22-27.

Chen, T., Chen, C., Lan, J. and Wang, M. (1984) 'A practical approach to monitoring the wear of grinding wheel in cylindrical grinding process', Japan Society of Precision Engineering, pp.300-305.

Chidambaram, S., Pei, Z.J. and Kassir, S. (2003a) 'Fine grinding of silicon wafers: a mathematical model chuck shape', International Journal of Machine Tools \& Manufacture, Vol. 43, pp.739-746.

Chidambaram, S., Pei, Z.J. and Kassir, S. (2003b) 'Fine grinding of silicon wafers: a mathematical model for grinding marks', International Journal of Machine Tools \& Manufacture, Vol. 43, pp.1595-1602.

Couey, J.A., Marsh, E.R., Knapp, B.R. and Vallance, R.R. (2005) 'A comparison of force and acoustic emission sensors in monitoring precision cylindrical grinding', Precision Engineering, http://www.sciencedirect.com/science?_ob=IssueURL\&_tockey $=\% 23$ TOC\% $235761 \% 239999 \% 23999999999 \% 2399999 \% 23 F L A \% 23$ Articles_in_Press\&_auth=y\&view=c \&_acct $=$ C000014439\&_version $=1 \&$ urlVersion $=0$ \&_us 
Dornfeld, D.A., Lee, Y. and Chang, A. (2003) 'Monitoring of ultraprecision machining processes', International Journal of Advanced Manufacturing Technology, Vol. 21, pp.571-578.

Drew, S.J., Mannan, M.A., Ong, K.L. and Stone, B.J. (2001) 'The measurement of forces in grinding in the presence of vibration', International Journal of Machine Tools \& Manufacture, Vol. 41, No. 4, pp.509-520.

He, X.S. (1985) 'Research of a practical adaptive control system for external cylindrical grinding process', Proceedings of the International Machine Tool Design and Research Conference, pp.169-175.

Knapp, B. (2002) On the Use of an Instrumented Spindle to Determine the Effects of Machine Stiffness in Grinding Brittle Materials, PhD thesis, Penn State University, University Park, Pennsylvania.

Lezanski, R., Rafalowicz, J. and Jedrzejewski, J. (1993) 'An intelligent monitoring system for cylindrical grinding', Annals of the CIRP, Vol. 42, No. 1, pp.393-396.

Li, Z.C., Lin, B., Xu, Y.S. and Hu, J. (2002) 'Experimental studies on grinding forces and force ratio of the unsteady-state grinding technique', Journal of Materials Processing Technology, Vol. 129, Nos.1-3, pp.76-80.

Lin, B., Yu, S.Y. and Wang, S.X. (2003) 'An experimental study on molecular dynamics simulation in nanometer grinding', Journal of Materials Processing Technology, Vol. 138, pp.484-488.

Malkin, S. (1989) Grinding Technology: Theory and Application of Machining Abrasives, Ellis Horwood, Chichester and John Wiley, New York.

Marsh, E., Grejda, R. and Knapp, B. (2000) 'Superabrasive process optimization through force measurement', Abrasives, pp.29-33.

Marsh, E., Grejda, R., Arneson, D., Liebers, M. and Martin, D. (1998) 'Instrumented testbed for precision grinding', Abrasives, pp.36-46.

O'Connor, B.P., Marsh, E.R. and Couey, J.A. (2005) 'On the effect of crystallographic orientation on ductile material removal in silicon', Precision Engineering, Vol. 29, No. 1, pp.113-123.

Oliveira, J.F.G. and Valente, C.M.O. (2004) 'Fast grinding process control with AE modulated power signals', Annals of the CIRP, Vol. 53, No. 1, pp.267-270.

Pei, Z.J. and Strasbaugh, A. (2001) 'Fine grinding of silicon wafers', International Journal of Machine Tools \& Manufacture, Vol. 41, pp.659-672.

Pei, Z.J. and Strasbaugh, A. (2002) 'Fine grinding of silicon wafers: designed experiments', International Journal of Machine Tools \& Manufacture, Vol. 42, pp.395-404.

Ramos, J.C., Vinolas, J. and Nieto, F.J. (2001) 'A simplified methodology to determine the cutting stiffness and the contact stiffness in the plunge grinding process', International Journal of Machine Tools \& Manufacture, Vol. 41, pp.33-49.

Sun, W., Pei, Z.J. and Fisher, G.R. (2004) 'Fine grinding of silicon wafers: a mathematical model for wafer shape', International Journal of Machine Tools \& Manufacture, Vol. 44, pp.707-716.

Tonshoff, H.K., Friemuth, T. and Becker, J.C. (2002) 'Process monitoring in grinding', Annals of the CIRP, Vol. 51, No. 2, pp.551-571.

\section{Note}

${ }^{1}$ Kistler Instrument Company, www.kistler.com, Winterthur, Switzerland. 